\title{
Public's Intention and Influencing Factors of Dockless Bike-Sharing in Central Urban Areas: A Case Study of Lanzhou City, China
}

\author{
Wei Ji ${ }^{1,2}$, Chengpeng Lu ${ }^{1,2, *}$, Jinhuang Mao ${ }^{1,2}$, Yiping Liu ${ }^{1}$, Muchen Hou ${ }^{1,2}$ and Xiaoli Pan ${ }^{1,2}$ \\ 1 Institute of County Economic Development \& Rural Revitalization Strategy, \\ Lanzhou University, Lanzhou 730000, China; jiw19@lzu.edu.cn (W.J.); maojh@lzu.edu.cn (J.M.); \\ liuyiping@lzu.edu.cn (Y.L.); houmch20@lzu.edu.cn (M.H.); panxl20@lzu.edu.cn (X.P.) \\ 2 School of Economics, Lanzhou University, Lanzhou 730000, China \\ * Correspondence: lcp@lzu.edu.cn
}

check for updates

Citation: Ji, W.; Lu, C.; Mao, J.; Liu, Y.; Hou, M.; Pan, X. Public's Intention and Influencing Factors of Dockless Bike-Sharing in Central Urban Areas: A Case Study of Lanzhou City, China. Sustainability 2021, 13, 9265. https://doi.org/10.3390/su13169265

Academic Editors: Baojie He, Ayyoob Sharifi, Chi Feng and Jun Yang

Received: 26 July 2021

Accepted: 17 August 2021

Published: 18 August 2021

Publisher's Note: MDPI stays neutral with regard to jurisdictional claims in published maps and institutional affiliations.

Copyright: (c) 2021 by the authors. Licensee MDPI, Basel, Switzerland. This article is an open access article distributed under the terms and conditions of the Creative Commons Attribution (CC BY) license (https:/ / creativecommons.org/licenses/by/ $4.0 /)$.

\begin{abstract}
Taking the main district in Lanzhou city of China as an example, the questionnaires were designed and distributed, and then the effects of five factors, i.e., behavioral attitude, subjective norm, perceived behavioral control, perceived ease of use and perceived usefulness, on the behavioral intention of dockless bike-sharing (DBS) use were empirically analyzed based on the integrated model of technology acceptance model (TAM) and the theory of planned behavior (TPB) as well as the structural equation model. Results show that the five factors all impose significantly positive effects on the public's behavioral intention of DBS use but differ in influencing degrees. Behavioral attitude, subjective norm and perceived behavioral control can all directly affect the public's behavioral intention of DBS use, with direct influence coefficients of $0.691,0.257$ and 0.198 , while perceived ease of use and perceived usefulness impose indirectly effects on behavioral intention, with indirect influence coefficients of 0.372 and 0.396 . Overall, behavioral attitude imposes the most significant effect, followed by perceived ease of use, perceived usefulness and subjective norm, and finally perceived behavioral control. This indicates that the public's behavioral intention of DBS use depends heavily on their behavioral attitude towards the shared bikes. In view of the limited open space of the main district in Lanzhou, the explosive growth of shared bikes, oversaturated arrangements, disordered competition, unclear and unscientific divisions of parking regions, and hindrance of traffic, this study proposes a lot of policy suggestions from the research results. A series of supporting service systems related to DBS should be formulated. The shared bikes with different characteristics should be launched for different age groups, gender groups and work groups. The corresponding feedback platform for realtime acquisition, organization, analysis and solution of data information, as well as the adequate platform feedback mechanism, should be established.
\end{abstract}

Keywords: dockless bike-sharing (DBS); behavioral intention; influencing factors; theory of planned behavior (TPB); Lanzhou City

\section{Introduction}

Urban traffic problem now has gradually become one of the main factors that affect the improvement of urban built environment in China [1]. Green travel is exactly the reflection and reformation of current urban traffic development [2]. Bike sharing, as a novel travel mode featured by the Internet and sharing, offers a new transport mode for short trips and enhances the connections with other modes such as bus and subway [3-6]. Bike sharing can not only satisfy the heavy demand for short trips but also contribute to solving a lot of urban stubborn diseases such as traffic jams and environmental pollution [7], thereby injecting new vitality into the urban traffic system. Bike sharing can make urban traffic services more diversified and intelligent [8] and play quite an active role in establishing a green travel system. However, with the rapid development of mobile information 
communication technology and full penetration into social life, time, space and distance have been highly compressed, leading to the transformation of daily lives of residents [9]. Meanwhile, temporal-spatial elasticity and flexibility of some activities such as shopping, leisure and commuting have been enhanced [10], and the public's intention and choice to use shared bike services also show some new features [11].

Over the last several years, China has experienced a fast development in DBS, which provides great convenience for travelers [12]. It is a crucial supplement for other traffic modes in cities. Understanding the travel mobility and traffic demand of DBS is conducive to many urban problems such as urban development and traffic management [13-15]. Currently, scholars have mainly investigated cycling trips on the planning of public bike docks and the arrangement model $[16,17]$ and explored the influencing factors of public bike trips from the perspectives of the built environment, land utilization and user characteristics [18-24]. The DBS has been poorly investigated to date. Most existing studies have laid the research emphasis on temporal-spatial distribution characteristics [25-27], use travel features [28] and the influencing factors based on the spatial scale [29]. Accompanied with increasing urban traffic pressure and environmental pressure, bike sharing has become one of the most basic daily living consumptions for the public. Investigating the use of shared bikes by residents should include both in-depth studies at a macro spatial scale and the discussions of transportation behavioral intentions of urban residents and the related influencing factors from the micro individual perspective.

Currently, some studies have revealed that individual psychological factors imposed significant effects on the residents' intention to use public bikes [30,31]. Accordingly, whether individual psychological factors also significantly affect the use of DBS. In view of this, this study selected the main urban zone in Lanzhou, China, i.e., Chengguan District, Qilihe District, Xigu District and Anning District as research areas. By taking DBS as an example, the integrated model of the public's intentions of DBS use was established based on the technology acceptance model and the theory of planned behavior. In combination with the structural equation model, the subjective psychological factors that affect the public's intentions of DBS use were explored so as to make up for the shortcomings of investigating travel behaviors in geographic space. Meanwhile, this study can provide decision-making basis for the governmental administration departments to adequately guide green travel.

\section{Study Area and Methods}

\subsection{Study Area}

Lanzhou city is located at the geometric center of China's land territory, which is also an important center city, industrial base and comprehensive transportation junction in the northwest of China. As also shown in Figure 1, Lanzhou is a key node city in Silk Road Economic Belt. Five districts (Chengguan, Qilihe, Xigu, Anning and Honggu), five counties (Yongdeng, Yuzhong and Gaolan), 1 national-level new district (Lanzhou New District), and two national-level development zones (Lanzhou High-Tech Development Zone and Lanzhou Economic and Technological Development Zone) are under the administration. Lanzhou covers a total area of $13,100 \mathrm{~km}^{2}$ and an urban area of $1631.6 \mathrm{~km}^{2}$. According to the 7th National Census data, the permanent resident pollution in Lanzhou reaches up to 435.94 million. DBS has successively appeared in Lanzhou since March 2017. Currently, over 300,000 shared bikes and electrical bikes owned by different companies such as Hellobike, Qingju and Mobike were put on the market in Lanzhou. Additionally, 1 subway line, 27 intercity bus lines, 52 urban-rural public bus lines and 11 micro-bus lines operate normally in Lanzhou. According to The Investigation Report of Xinhua Green Travel Index (2017), Lanzhou ranks first in terms of green travel satisfaction degree [32]. The respondents are satisfied with the infrastructure construction, service and policies of urban green travel. The shared bikes can provide the residents with great convenience owing to the design concept of go and stop at any time. However, due to limited urban spatial resources, unclear and unscientific division of bike parking zones can not only cause the 
wasting of resources and affect urban appearance but also result in the congestion on sidewalk road and hinder the traffic [33].

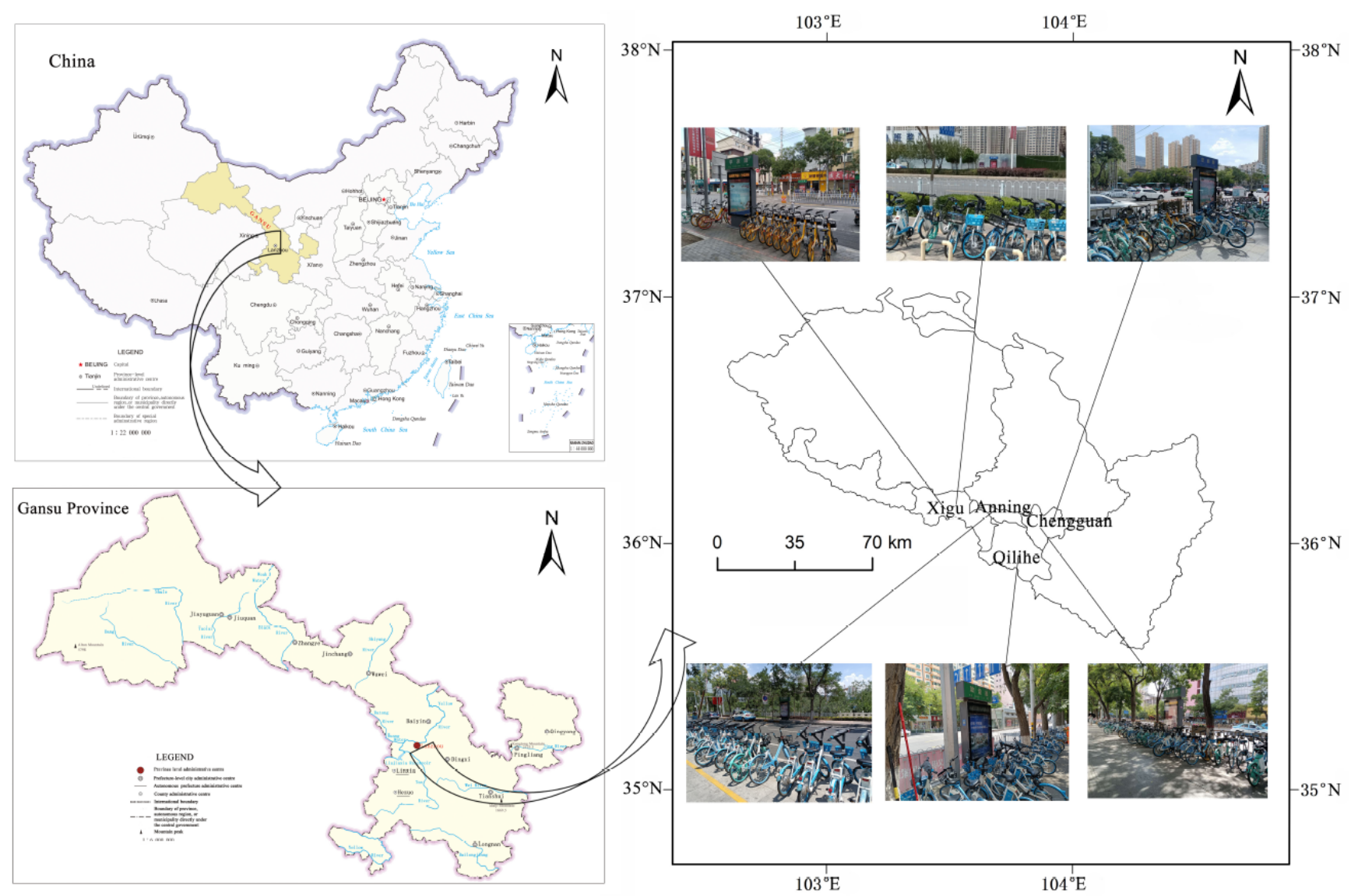

Figure 1. Location of the Lanzhou City.

\subsection{Integrated Model}

Theory of reasoned action (TRA) is one of the most basic theories to investigate cognitive behaviors, which can be used for predicting behaviors and behavioral intention including both general social activities and consumption activities [34]. TRA advocates that individual behaviors are subjected to behavioral intention while the behavior intention is codetermined by attitude and subjective norms. However, TRA is only applicable to predicting the behaviors fully controlled by the mind. Therefore, on the basis of TRA, Ajzen added a new predictive variable, i.e., perceived behavioral control, and established the Theory of Planned Behavior (TPB) [35]. Nevertheless, TPB still exists limitations in the adoption of new technologies. For this reason, Davis added two factors, i.e., perceived ease of use and perceived usefulness, to investigate users' using behaviors of information system, and proposed the technology acceptance model (TAM), which holds the opinion that both perceived case of use and perceived usefulness can affect the behavioral attitude and thereby affect the behavioral intention [36]. On the basis of TRA, the integrated model organically combines TPB and TAM, in which behavioral intention is regarded as the outcome variable, and behavioral attitude, subjective norm, perceived behavioral control, perceived case of use and perceived usefulness are five causal variables affecting the behavioral intention [37].

\subsection{Structural Equation Model (SEM)}

The structural equation model, integrating factor analysis and path analysis, can be used for analyzing both direct and indirect relations among variables. A complete structural equation includes two equations, i.e., the measurement equation that describes 
the relation between the latent variable and measured variable, and the structural equation that describes the relationship between latent variables $[38,39]$. According to the structural relationship among variables and the definitions of variables as shown in Table 1, the model including 6 latent variables and 23 measured variables was established, as shown in Figure 2.

Table 1. Variable definition.

\begin{tabular}{|c|c|c|c|}
\hline Latent Variable & Measured Variable & $\begin{array}{l}\text { Number of } \\
\text { Questions }\end{array}$ & Label \\
\hline Behavioral attitude $\left(\mathrm{X}_{1}\right)$ & $\begin{array}{l}\text { It is convenient to use the shared bike. } \\
\text { It is comfortable to use the shared bike. } \\
\text { It is interesting to use the shared bike. } \\
\text { It is valuable to use the shared bike. }\end{array}$ & 4 & $\begin{array}{l}X_{11} \\
X_{12} \\
X_{13} \\
X_{14}\end{array}$ \\
\hline Subjective norm $\left(\mathrm{X}_{2}\right)$ & $\begin{array}{c}\text { Family members think we should use } \\
\text { the shared bike. } \\
\text { Friends think we should use the } \\
\text { shared bike. } \\
\text { Schoolmates or workmates think we } \\
\text { should use the shared bike. }\end{array}$ & 3 & $\begin{array}{l}x_{21} \\
x_{22} \\
x_{23}\end{array}$ \\
\hline $\begin{array}{l}\text { Perceived behavioral } \\
\text { control }\left(X_{3}\right)\end{array}$ & $\begin{array}{l}\text { Possess the mobile phone skills of using } \\
\text { the shared bike. } \\
\text { Possess the riding skills of using the } \\
\text { shared bike. } \\
\text { Possess the physical fitness of using the } \\
\text { shared bike. } \\
\text { Possess the psychological quality of } \\
\text { using the shared bike. }\end{array}$ & 4 & $\begin{array}{l}x_{31} \\
x_{32} \\
x_{33} \\
x_{34}\end{array}$ \\
\hline Perceived usefulness $\left(\mathrm{X}_{4}\right)$ & $\begin{array}{c}\text { Using the shared bike can protect the } \\
\text { environment. } \\
\text { Using the shared bike can avoid the } \\
\text { traffic jam. } \\
\text { Using the shared bike can enhance } \\
\text { travel efficiency. } \\
\text { Using the shared bike can contribute to } \\
\text { taking exercise. } \\
\text { Using the shared bike can } \\
\text { save resources. }\end{array}$ & 5 & $\begin{array}{l}\mathrm{X}_{41} \\
\mathrm{X}_{42} \\
\mathrm{X}_{43} \\
\mathrm{X}_{44} \\
\mathrm{X}_{45}\end{array}$ \\
\hline Perceived ease of use $\left(X_{5}\right)$ & $\begin{array}{l}\text { The registration procedure for the use of } \\
\text { shared bike is easy and convenient. } \\
\text { The shared bike can park conveniently. } \\
\text { Payment for the use of shared bike is } \\
\text { easy and economical. } \\
\text { The shared bike possesses excellent } \\
\text { performance. }\end{array}$ & 4 & $\begin{array}{l}X_{51} \\
X_{52} \\
X_{53} \\
X_{54}\end{array}$ \\
\hline Behavioral intention $\left(X_{6}\right)$ & $\begin{array}{l}\text { With the intention to use the shared bike } \\
\text { under the current condition. } \\
\text { With the intention to use the shared bike } \\
\text { in the future. } \\
\text { With the intention to recommend the } \\
\text { shared bike to other people. }\end{array}$ & 3 & $\begin{array}{l}X_{62} \\
x_{63}\end{array}$ \\
\hline
\end{tabular}

Conclusively, based on TAM and TPB, this study employed SEM for empirically analyzing the effects of five factors, i.e., behavioral attitude, subjective norm, perceived behavioral control, perceived ease of use and perceived usefulness, on the public's behavioral intention of DBS use. The whole research process is shown in Figure 3. 


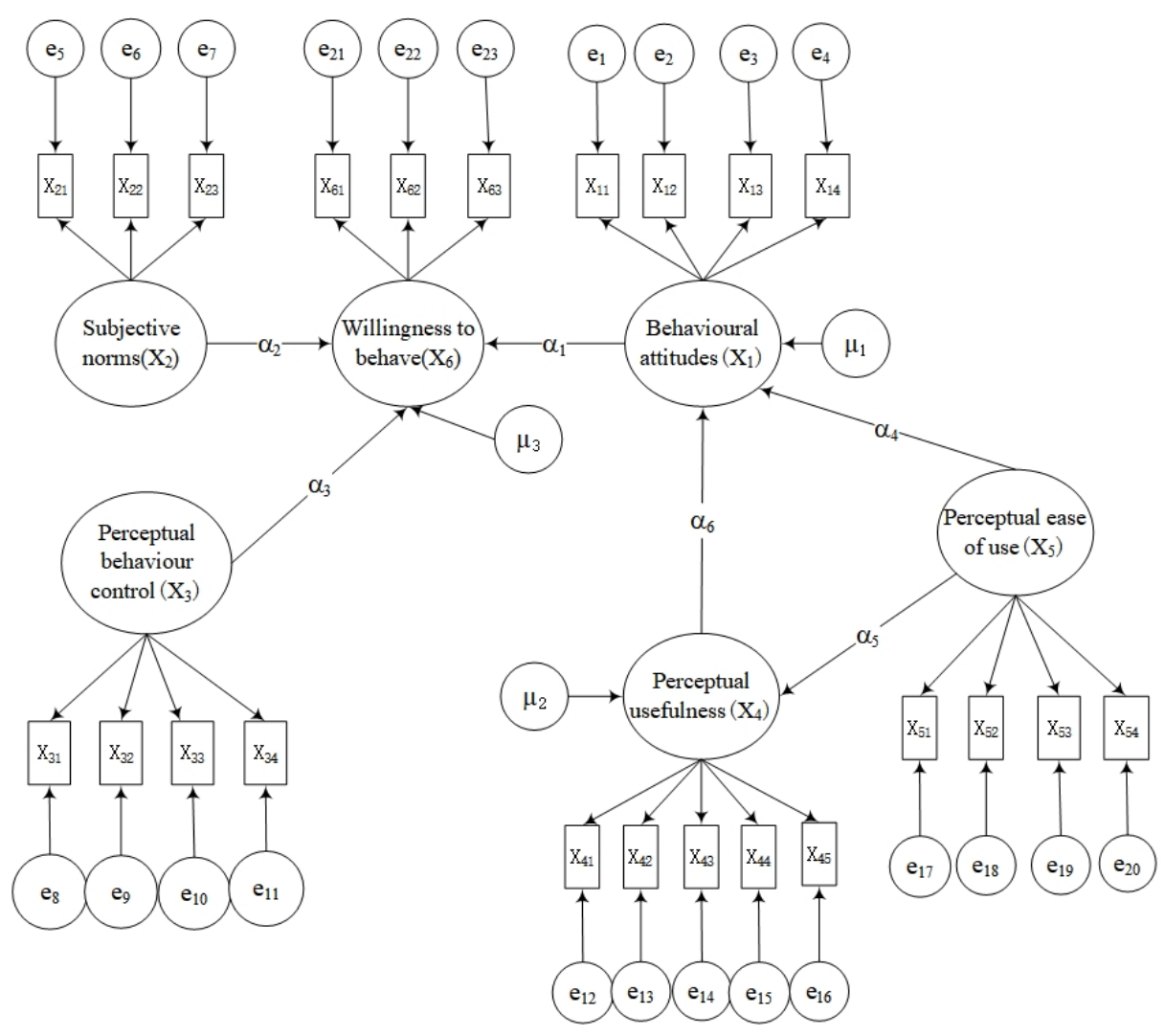

Figure 2. Path analysis results of structure equation model.

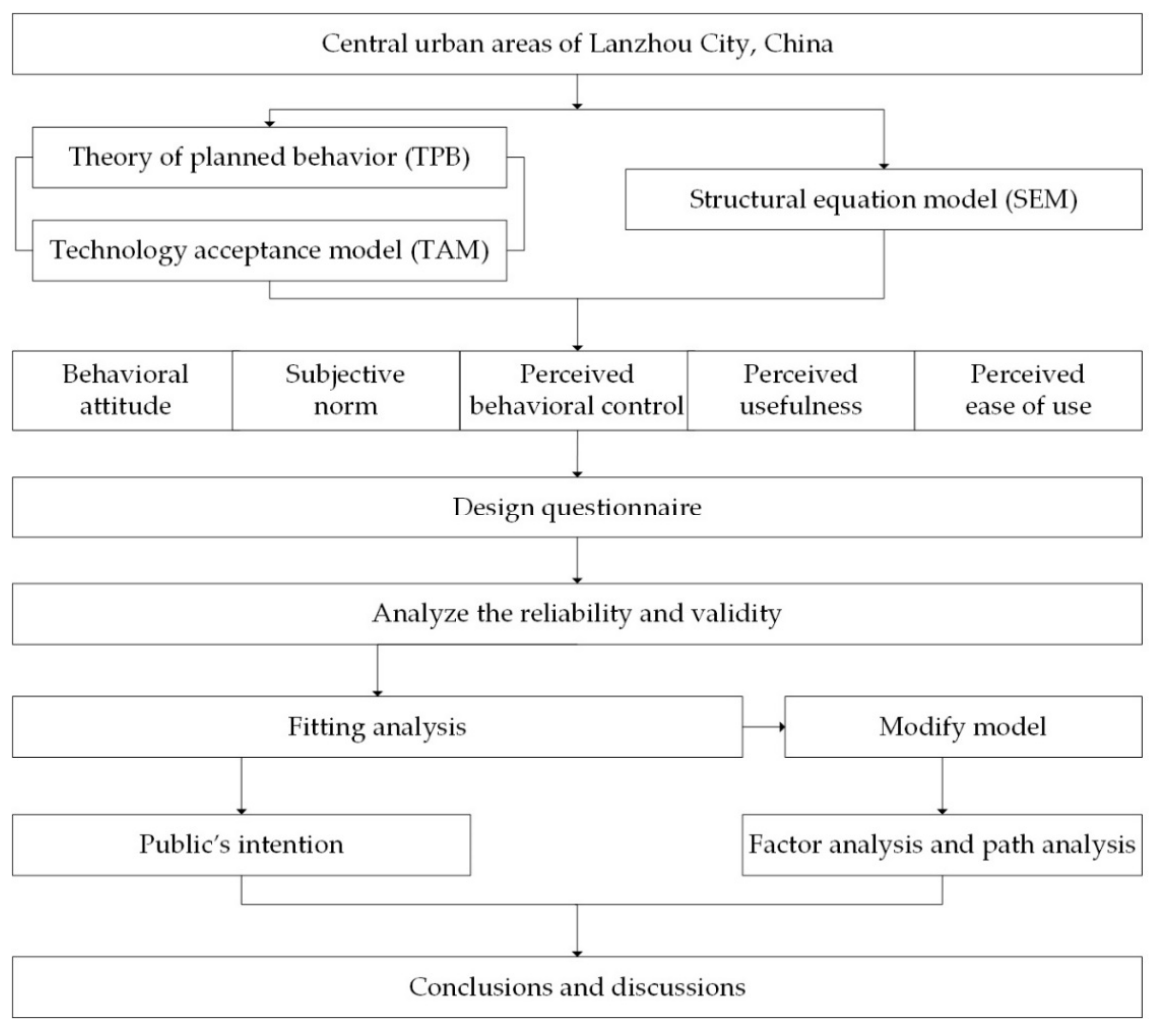

Figure 3. Technology roadmap. 


\subsection{Data Sources}

Based on TPB and the scale of TAM [40,41], the questionnaire was designed by consulting the related references [42-45]. The present questionnaire was implemented by an authoritative survey company in China, WJX.cn. In order to ensure the respondents have ever used the shared bikes, the jumping question was set in the questionnaire. For example, the respondent can end the questionnaire if he or she gives the answer 'Never use the shared bike'. In other words, the users that never use the shared bike can jump to the end of the questionnaire after filling in the basic information. The detailed contents of the questionnaire are shown in Table 2. The distribution and collection of the questionnaires were performed from May to July 2021. To be specific, 700 questionnaires were distributed, and 680 questionnaires were collected, of which 52 questionnaires were judged as invalid. Therefore, 628 valid questionnaires were collected, while 52 questionnaires from the respondents who gave the answer 'Never use the shared bike' or answered the question within a short time were considered invalid. Therefore, 628 valid questionnaires were collected. Table 3 shows the basic characteristics of the sample data. Among all respondents, 54\% were female, that is, the female respondents slightly exceeded male respondents. In terms of age, $14.04 \%$ of the respondents were within the age range of 12 18. According to the Regulations for the Implementation of Road Traffic Safety Law, the cyclists should be aged 18 or above. The respondents under the age of 12 were rejected with the answer 'Never use the shared bike'. An overwhelming majority of respondents (with a proportion of $81.21 \%$ ) were 19 50 years old, which may be due to the fact that the residents in Lanzhou with an age of over 50 mainly use non-smart phones. Since the survey was performed in central downtown, the respondents showed favorable education degrees. A total of $66.08 \%$ of the respondents had a Bachelor degree or above, while $55.09 \%$ had a monthly income of below CNY 4000. This suggests that DBS is more preferred by low-income groups. In terms of the frequency of utilization, approximately $57.97 \%$ of users used the shared bikes $1 \sim 4$ times in one week, while $7.96 \%$ of users used the shared bikes over 16 times in one week; approximately $38.06 \%$ of users selected to use the shared bikes to reach railway stations, motor stations or subway stations. Obviously, DBS played an indispensable role in public transport connection. Overall, the structural characteristics of the respondents in this study fit well with the sociological population characteristics of the residents who use the shared bikes in previous studies $[46,47]$, which confirms the favorable representativeness of the samples in this study.

Table 2. Questionnaire design.

\begin{tabular}{ll}
\hline Question & Options \\
\hline $\begin{array}{l}\text { 1. Have you ever used the shared bikes? } \\
\text { 2. Your gender }\end{array}$ & A. Yes B. No (If you choose B, skip to the end) \\
3. Your age & A. Male B. Female \\
4. Your education background & A. 17 B.12-18 C.19-30 D.31-50 E. 50 \\
& D. Grimary school or below B. Middle school C. Undergraduate \\
5. Your occupation & A. Student B. Civil servant C. Worker D. Liberal profession E. \\
& Others \\
6. Your income & A. Below 2000 yuan B. 2000-4000 yuan C. $4000-6000$ yuan D. \\
& Above 6000 yuan \\
7. Your frequency of DBS use in one week & A. 1-4 times B. 5-8 times C. 9-12 times D. 13-16 times E. Over \\
& 16 times \\
8. Where is your cycling destination? & A. School or work unit B. Shopping mall or entertainment venue \\
& C. Railway station, subway station or bus station D. Others \\
9. Your attitude towards the use of shared bikes & A. It is convenient to use the shared bikes. \\
& B. It is comfortable to use the shared bikes. \\
& C. It is interesting to use the shared bikes. \\
\end{tabular}


Table 2. Cont.

\section{Question}

10. Who imposes great influence on your selection of the shared bikes?

11. Which kind of ability is needed for your use of shared bikes?

12. What are the advantages of DBS use?

13. What is the greatest convenience in the use of shared bikes?

14. Your future attitude towards the use of shared bikes

\section{Options}

A. Family member B. Friend C. Schoolmate or colleague

A. Mobile phone performance B. Cycling skill C. Physical fitness

D. Psychological quality

A. DBS use can protect the environment.

B. DBS use can avoid traffic jams.

C. DBS use can enhance traveling efficiency.

D. DBS use can provide physical exercise.

E. DBS use can save resources.

A. It is convenient to register the usage procedure.

B. It is convenient to park the shared bikes.

C. It is convenient to pay the cost of using shared bikes.

D. The shared bikes have good performance.

A. I'm willing to use the shared bikes under current conditions.

B. I'm willing to use the shared bikes in future.

C. I'm willing to recommend shared bikes to others.

Table 3. Basic characteristics of sample data.

\begin{tabular}{|c|c|c|c|c|c|c|c|}
\hline $\begin{array}{l}\text { Statistical } \\
\text { Indicator }\end{array}$ & $\begin{array}{l}\text { Classification } \\
\text { Indicator }\end{array}$ & $\begin{array}{c}\text { Number of } \\
\text { People }\end{array}$ & $\begin{array}{l}\text { Proportion } \\
\text { in the Valid } \\
\text { Samples }(\%)\end{array}$ & $\begin{array}{l}\text { Statistical } \\
\text { Indicator }\end{array}$ & $\begin{array}{l}\text { Classification } \\
\text { Indicator }\end{array}$ & $\begin{array}{c}\text { Number of } \\
\text { People }\end{array}$ & $\begin{array}{l}\text { Proportion } \\
\text { in the Valid } \\
\text { Samples (\%) }\end{array}$ \\
\hline \multirow[b]{2}{*}{ Gender } & Male & 289 & 46.02 & \multirow[t]{2}{*}{ Profession } & Student & 208 & 33.12 \\
\hline & Female & 339 & 53.98 & & Civil servant & 214 & 34.08 \\
\hline \multirow[t]{4}{*}{ Age } & $12-18$ & 88 & 14.01 & & \multirow{4}{*}{$\begin{array}{l}\text { Worker } \\
\text { Liberal } \\
\text { profession } \\
\text { Others } \\
\text { Below CNY } \\
2000\end{array}$} & 37 & 5.89 \\
\hline & 19-30 & 378 & 60.19 & & & 84 & 13.38 \\
\hline & $31-50$ & 132 & 21.02 & & & 85 & 13.54 \\
\hline & $>50$ & 30 & 4.78 & Income & & 220 & 35.03 \\
\hline \multirow[t]{4}{*}{$\begin{array}{l}\text { Degree of } \\
\text { education }\end{array}$} & $\begin{array}{l}\text { Primary or } \\
\text { below }\end{array}$ & 18 & 2.97 & & \multirow{4}{*}{$\begin{array}{c}\text { CNY } \\
2000-4000 \\
\text { CNY } \\
4000-6000 \\
\text { Above CNY } \\
6000\end{array}$} & 126 & 20.06 \\
\hline & $\begin{array}{l}\text { Middle } \\
\text { school }\end{array}$ & 195 & 31.05 & & & 188 & 29.94 \\
\hline & Undergraduate & 286 & 45.54 & & & 94 & 14.97 \\
\hline & $\begin{array}{l}\text { Postgraduate } \\
\text { or above }\end{array}$ & 129 & 20.54 & & & & \\
\hline
\end{tabular}

\section{Results}

\subsection{Factor Analysis of Residents' Behavioral Intention of Using the Shared Bikes}

The reliability and validity of the questionnaire were analyzed by SPSS23.0. The Cronbach's $\alpha$ coefficient was selected as the measuring index of reliability [47]. Through measurements, the Cronbach's $\alpha$ coefficients of behavioral attitude, subjective norm, perceived behavioral control, perceived usefulness, perceived ease of use, and behavioral intention were $0.742,0.765,0.801,0.831,0.859$ and 0.728 , respectively, while the overall Cronbach's $\alpha$ coefficient was 0.907 , indicating the high reliability of both the whole questionnaire and various dimensions. The validity was measured via the KMO test and Bartlett sphericity test [48]. The overall KMO value of six latent variables was 0.907 , which has also passed the Bartlett sphericity test. Accordingly, factory analysis can be performed on the questionnaire. The correlation coefficient matrix was then constructed by Amos23.0, and the path coefficient in the model was estimated via maximum likelihood estimation. Before parameter estimation, the model was first fitted. The goodness of fit of the model was evaluated by 11 specific indexes. In the initial model fitting, the Chi-square freedom degree ratio (c2/df) was 4.563, suggesting the model could not adequately reflect the 
questionnaire and needed to be improved [49]. Based on the principle of reasonableness and specification, the model was modified in accordance with the Amos correction index so that various fitting indexes can finally satisfy the test requirements (see Table 4). Overall, the fitting was favorable, suggesting high compatibility between the model and the present questionnaire. The integrated model based on TAM and TPB is applicable to the studies in the traffic domain, which can well explain the public's behavioral intentions of using the shared bikes.

Table 4. Model fitting indexes and the fitting results.

\begin{tabular}{ccccc}
\hline Fitting Index & Specific Index & Ideal Value & $\begin{array}{c}\text { Model } \\
\text { Estimated Value }\end{array}$ & Test Result \\
\hline \multirow{3}{*}{$\begin{array}{c}\text { Measure of } \\
\text { absolute fit }\end{array}$} & GFI & $>0.90$ & 0.917 & Accepted \\
& AGFI & $>0.90$ & 0.927 & Accepted \\
& RMMR & $<0.05$ & 0.043 & Accepted \\
& RMEA & $<0.08$ & 0.068 & Accepted \\
\hline Measure of & NFI & $>0.90$ & 0.920 & Accepted \\
incremental fit & CFI & $>0.90$ & 0.930 & Accepted \\
& IFI & $>0.90$ & 0.942 & Accepted \\
& PGFI & $>0.90$ & 0.915 & Accepted \\
Measure of & PNFI & $>0.50$ & 0.641 & Accepted \\
simple fit & NC (Chi-square & & 0.683 & Accepted \\
& freedom degree & $1<\mathrm{NC}<3$ & 2.830 & Accepted \\
\hline
\end{tabular}

The standard loading factors between 23 observable variables in parameter test results and the corresponding latent variables ranged from 0.545 to 0.891 , which all exceeded 0.5, suggesting a favorable basic fit measure. The values of C.R all exceeded 1.96, that is, the parameter estimated values all reached the significance level of $1 \%$ (Table 5). The standard factor loads of four measured variables regarding behavioral attitude were $0.690,0.776$, 0.635 and 0.862 , respectively, suggesting the convenience, comfort, interesting degree and value of using the shared bikes can significantly affect the public's opinions and behavioral intentions of DBS use. The standard factor loads of three measured variables regarding subjective norm were $0.651,0.891$ and 0.862 , respectively, suggesting that residents are subjected to positive influences from family members, friends and schoolmates (workmates) when using the shared bikes. The standard factor loads of four measured variables regarding perceived behavioral control were $0.545,0.710,0.765$ and 0.621 , respectively, suggesting positive effects of the mobile skill, riding skill, physical fitness and psychological quality, especially physical fitness, on the use of shared bikes. The standard factor loads of five measured variables regarding perceived usefulness were $0.767,0.679,0.701,0.595$ and 0.644 , respectively, suggesting that DBS use can bring about useful experiences such as environmental protection, enhancement of efficiency, bodybuilding and energy conservation, among which environmental protection was most remarkable. The standard factor loads of four measured variables regarding perceived ease of use were $0.690,0.801,0.778$ and 0.791 , respectively, suggesting that the registration program, the parking convenience, payment and program and the performance of the shared bikes affect the public's perceiving ease degree of DBS use; in particular, the parking convenience imposes most significant effect. The standard factor loads of three measured variables regarding behavioral intention were $0.596,0.674$ and 0.713 , respectively, indicating that the residents not only are willing to use the shared bikes but also encourage and advocate the other people to use the shared bikes. 
Table 5. Model fitting indexes and the fitting results.

\begin{tabular}{|c|c|c|c|c|}
\hline Latent Variable & $\begin{array}{c}\text { Measured } \\
\text { Variable }\end{array}$ & $\mathbf{P}$ & C.R Value & Standard Factor Load \\
\hline \multirow{4}{*}{ Behavioral attitude } & $x_{11}$ & & & 0.690 \\
\hline & $\mathrm{X}_{12}$ & $* * *$ & 14.882 & 0.776 \\
\hline & $\mathrm{X}_{13}$ & $* * *$ & 12.314 & 0.635 \\
\hline & $\mathrm{X}_{14}$ & & & 0.632 \\
\hline \multirow{3}{*}{ Subjective norm } & $x_{21}$ & $* * *$ & 12.453 & 0.651 \\
\hline & $x_{22}^{21}$ & $* * *$ & 15.428 & 0.891 \\
\hline & $X_{23}$ & $* * *$ & 15.270 & 0.862 \\
\hline \multirow{4}{*}{$\begin{array}{l}\text { Perceived behavioral } \\
\text { control }\end{array}$} & $X_{31}$ & & & 0.545 \\
\hline & $x_{32}$ & $* * *$ & 14.360 & 0.710 \\
\hline & $x_{33}$ & $* * *$ & 14.782 & 0.765 \\
\hline & $X_{34}$ & $* * *$ & 11.917 & 0.621 \\
\hline \multirow{5}{*}{ Perceived usefulness } & $X_{41}$ & & & 0.767 \\
\hline & $X_{42}$ & $* * *$ & 12.835 & 0.679 \\
\hline & $\mathrm{X}_{43}$ & $* * *$ & 13.378 & 0.701 \\
\hline & $\mathrm{X}_{44}$ & $* * *$ & 11.666 & 0.595 \\
\hline & $\mathrm{X}_{45}$ & $* * *$ & 12.350 & 0.644 \\
\hline \multirow{4}{*}{ Perceived ease of use } & $X_{51}$ & & & 0.690 \\
\hline & $X_{52}$ & $* * *$ & 14.986 & 0.801 \\
\hline & $X_{53}$ & $* * *$ & 14.827 & 0.778 \\
\hline & $X_{54}$ & $* * *$ & 14.892 & 0.791 \\
\hline \multirow{3}{*}{ Behavioral intention } & $X_{61}$ & & & 0.596 \\
\hline & $x_{62}$ & $* * *$ & 12.827 & 0.674 \\
\hline & $x_{63}$ & $* * *$ & 14.253 & 0.713 \\
\hline
\end{tabular}

Note: *** suggests the significance at the level of $1 \%$, and C.R value equals the $t$ value (the same below).

\subsection{Analysis of the Influencing Factors of the Public's Behavioral Intention of DBS Use}

Figure 4 shows the relations among six latent variables, i.e., behavioral attitude, subjective norm, perceived behavioral control, perceived usefulness, perceived ease of use and behavioral intention. Table 6 displays the direct, indirect and total effects of the former five factors on behavioral intention. The following conclusions can be drawn.

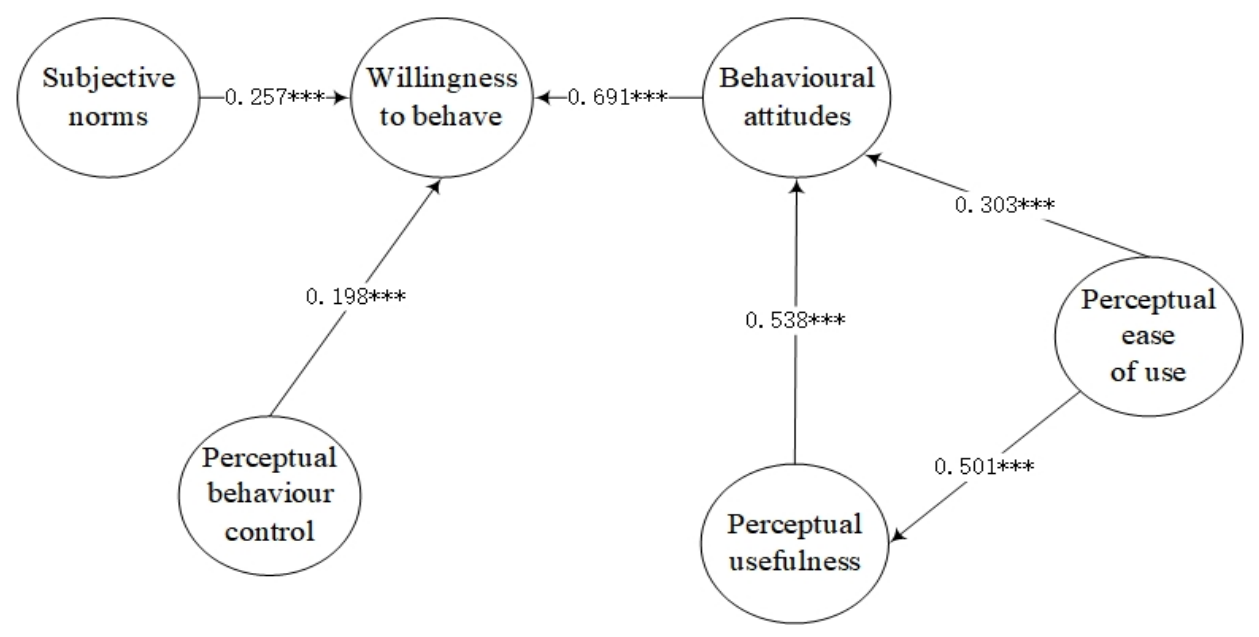

Figure 4. Path analysis results of structure equation model. Note: ${ }^{* *}$ suggests the significance at the level of $1 \%$. 
Table 6. Effects of different variables on the willingness to use shared bikes.

\begin{tabular}{cccc}
\hline \multirow{2}{*}{ Variables } & \multicolumn{3}{c}{ Behavioral Intention } \\
\cline { 2 - 4 } & Direct Effect & Indirect Effect & Total Effect \\
\hline Behavioral attitude & 0.691 & - & 0.691 \\
Subjective norm & 0.257 & - & 0.257 \\
Perceived behavioral control & 0.198 & - & 0.198 \\
Perceived usefulness & - & 0.372 & 0.372 \\
Perceived ease of use & - & 0.396 & 0.396 \\
\hline
\end{tabular}

- Behavioral attitude can directly affect behavioral intention, with an influence value of 0.691. Owing to the convenience, comfort, interestingness and value, the public shows positive attitudes towards DBS use, among which convenience and comfort impose most significant effects. Therefore, enhancing the appearance and performance of the shared bikes and placing the shared bikes at the appropriable positions can contribute to enhancing the public's intention of using shared bikes.

- Subjective norms impose a direct effect on behavioral intention, with an influence value of 0.257 . The opinions of acquaintances show important references for the public's selection of shared bikes. The sense of trust in the surrounding acquaintances and both collective consciousness and sense of community in daily life can impose imperceptible effects on the public's psychological actives and use behaviors. The individual behavioral intentions are inclined to stay in step with the people around. Therefore, the business should consider the difference in different user groups and the propaganda of DBS when making operating strategies. Formulating different operating schemes based on population differences can enhance the irradiating effect on more users.

- Perceived behavioral control can directly affect behavioral intention, with an influence value of 0.198 . Both physical and psychological quality and riding skills can impose positive effects on the public's choice of DBS. The riding skill and physical fitness can significantly affect the perceived behavioral control. According to the questionnaires, it can be found that some residents are anxious about collisions with motor vehicles or passers-by under bad weather or traffic conditions. In addition to skill and physical fitness, residents still doubted the use of shared bikes. It is therefore recommended to add a bike lane and advocate the comity to pedestrians to alleviate the risk to a certain degree, thereby enhancing the residents' behavioral intention of using shared bikes.

- Perceived usefulness can affect the behavioral intention indirectly but impose a direct effect on the behavioral attitude, with influence values of 0.372 and 0.538 , respectively. Behavioral attitude plays a mediating role in directly affecting behavioral intention. This means that residents still enjoy both interestingness and convenience in DBS in addition to environmental protection, alleviation of traffic jams and the enhancement of traveling efficiency. Owing to the multiple advantages of riding the shared bikes, residents are more inclined to use the shared bikes.

- Perceived ease of use can indirectly affect behavioral intention while directly affect perceived usefulness and behavioral attitude, with influence values of 0.396, 0.501 and 0.303 , respectively. Perceived ease of use imposes indirect effect on behavioral intention via the following two paths: (1) Using behavioral attitude as the mediating variable and imposing indirect effect on the behavioral intention with an influence value of 0.209 , and (2) using perceived usefulness and behavioral attitude as two mediating variables and imposing direct effect on the behavioral intention with an influence value of 0.187 . DBS, as a new form of Internet bike renting mode, has the greatest advantage in freeing users from the parking stations and paying fees via the app on the mobile phone. Great convenience and flexibility change the residents opinion and attitude towards the use of shared bikes and enhance the use intention. 


\section{Conclusions and Discussion}

By taking the use of shared bikes in the main distribution of Lanzhou, China as an example, this study established the integrated model based on TAM, distributed 628 valid questionnaires and systematically analyzed the effects and the related influencing mechanism of five factors (i.e., behavioral attitude, subjective norm, perceived behavioral control, perceived ease of use and perceived usefulness) on the residents' behavioral intention of using shared bikes. The main conclusions are given in detail below.

Firstly, these five factors, i.e., behavioral attitude, subjective norm, perceived behavioral control, perceived ease of use and perceived usefulness, all have significantly positive effects on the public's behavioral intention of DBS use. To be specific, behavioral attitude, subjective norm and perceived behavioral control can directly affect the residents' behavioral intention, with direct influence coefficients of $0.691,0.257$ and 0.198 , respectively, while perceived usefulness and perceived ease of use impose indirect effects on behavioral intention, with indirect influence coefficients of 0.372 and 0.396 , respectively. Secondly, different subjective psychological factors affect behavioral intention to varying degrees. Overall, behavioral attitude imposes most significant effect, followed by perceived ease of use, perceived usefulness and subjective norm, while perceived behavioral control imposes the least effect. The public's behavioral intention of DBS use depends greatly on their behavioral attitude towards the shared bikes. Finally, behavioral attitude is an important bridge that integrating both TAM and TPB since perceived usefulness and perceived ease of use can indirectly affect the public's behavioral intention of DBS use via the mediating effect of behavioral attitude. Meanwhile, perceived ease of use can also indirectly affect the public's behavioral intention of DBS use via two mediating variables, namely, perceived usefulness and behavioral attitude.

This study focused on the behavioral intention of DBS use and analyzed the main influencing factors, which is expected to provide theoretical guidance for DBS enterprises in product design and marketing plans. The combination of TPB and SEM in urban sharing economy study is a beneficial attempt, which shows stronger explanatory power than a single use of TPB and SEM. An in-depth investigation of the main distribution of Lanzhou can reflect the overall characteristics of urban residents in DBS use to a certain degree but still needs to be improved. In future studies, we can expand the research range, prolong the research period and perform multi-scale and dynamic analysis. Next, this study laid the emphasis on the effects of the public's psychological factors on behavioral intention. By taking into account the built environment [50,51], topographic features [52] and climate factors [53], future studies will overall evaluate the effects of both subjective and objective factors on the public's behavioral intention of DBS use so as to obtain more strict and abundant conclusions.

Considering the limited open space of the main district in Lanzhou, the explosive growth of shared bikes, oversaturated arrangements, disordered competition, unclear and unscientific divisions of parking regions and hindrance of traffic, the following policy suggestions were proposed in combination with the present conclusions. Firstly, enterprises should work on technological innovation, optimization and upgrade, enhance the fit measure between software and hardware, and formulate a series of supporting service systems related to shared bikes. To be specific, the shared bikes can be equipped with some devices such as speed variators, shock attenuation devices, shelves and back seats, and some protective devices such as helmets and gloves to provide better riding experiences under the premise of ensuring bike quality. Secondly, the shared bikes with different characteristics should be launched for different age groups, gender groups and work groups. For example, pink bikes can be designed for women, the bikes with animal themes can be designed for students, while the elderly electric shared bikes should be added for the middle and old people. Thirdly, enterprises should set the corresponding feedback platform for real-time acquisition, organization, analysis and solution of data information, establish adequate platform feedback mechanism, build their WeChat official accounts and official websites and achieve good management, so as to reinforce the communication with 
users and the interaction between enterprises and users. Fourthly, the government should perfect the social credit system and incorporate DBS into the individual and enterprise credit system. On one hand, the enterprise credit system should be strengthened, that is, the credit system should be formulated to govern vicious competition among enterprises so as to encourage fair competition among enterprises, ensure the consumers' usage experiences and protect the related rights and interests of consumers. On the other hand, individual credit system should be established. For example, some improper illegal behaviors should be integrated into individual credit system via Internet, and then the users with insufficient credit scores will be restricted to a certain degree, which can better restrain user's DBS use behaviors and achieve civilized DBS use. Finally, as regard to the parking of shared bikes, the enterprise dominants should take reasonable distribution and grid administration. Various operators should reasonably allocate and distribute the shared bikes in accordance with usage density of shared bikes and population density, and increase the number of shared bikes at some public regions such as railway stations, subway stations, bus stations, schools, shopping malls and entertainment venues, which can facilitate connection with other transportation tools. Some supervision departments, such as the Bureau of Transport, the Bureau of Urban Administration and the Bureau of Market Supervision and Administration, should act in close coordination and strengthen communication and coordination to make concerted efforts and further standardize the parking regions of shared bikes. The parking system should set the function of temporary parking to provide the users with great convenience. Moreover, the convenient query function whether the destination can be parked or not should be added to avoid the extra dispatch fee for exceeding the designated parking area.

Author Contributions: Conceptualization, C.L.; methodology, W.J. and J.M.; formal analysis, W.J., Y.L.; investigation, W.J., J.M., Y.L., M.H., X.P. and C.L.; writing-original draft preparation, W.J. and C.L.; writing-review and editing, C.L. All authors have read and agreed to the published version of the manuscript.

Funding: This research was funded by National Natural Science Foundation of China (41701142), and Fundamental Research Funds for the Central Universities (2020jbkyjc002).

Institutional Review Board Statement: Not applicable.

Informed Consent Statement: Not applicable.

Data Availability Statement: The data used to support the findings of this study are available from the corresponding author upon reasonable request.

Conflicts of Interest: The authors declare no conflict of interest.

\section{References}

1. Guo, X.; Lu, C.; Sun, D.; Gao, Y.; Xue, B. Comparison of Usage and Influencing Factors between Governmental Public Bicycles and Dockless Bicycles in Linfen City, China. Sustainability 2021, 13, 6890. [CrossRef]

2. Bocker, L.; Anderson, E.; Uteng, T.P.; Throndsen, T. Bike sharing use in conjunction to public transport: Exploring spatiotemporal, age and gender dimensions in Oslo, Norway. Transp. Res. Part A Policy Pract. 2020, 138, 389-401. [CrossRef]

3. Molinillo, S.; Ruiz-Montanez, M.; Li'ebana-Cabanillas, F. User characteristics influencing use of a bicycle-sharing system integrated into an intermodal transport network in Spain. Int. J. Sustain. Transp. 2020, 14, 513-524. [CrossRef]

4. Zuo, T.; Wei, H.; Chen, N.; Zhang, C. First-and-last mile solution via bicycling to improving transit accessibility and advancing transportation equity. Cities 2020, 99, 102614. [CrossRef]

5. Shi, J.G.; Si, H.; Wu, G. Critical factors to achieve dockless bike-sharing sustainability in China: A stakeholder-oriented network perspective. Sustainability 2018, 10, 2090. [CrossRef]

6. Shi, Y. Research on Demand Forecasting and Scheduling Methods for Shared Bicycles; Beijing Jiaotong University: Beijing, China, 2019.

7. Bo, W.; Feng, Z.; Zongcai, W. The research on characteristics of urban activity space in Nanjing: An empirical analysis based on big data. Hum. Geogr. 2014, 29, 14-21.

8. Zhen, F.; Wei, Z.; Yang, S. The impact of information technology on the characteristics of urban resident travel: Case of Nanjing. Geogr. Res. 2009, 28, 1307-1317.

9. Yang, Y.X.; Heppenstall, A.; Turner, A.; Comber, A. A spatial and graph-based analysis of dockless bike sharing patterns to understand urban flows over the last mile. Comput. Environ. Urban Syst. 2019, 77, 101361. [CrossRef] 
10. Han, S.S. The spatial spread of dockless bike-sharing programs among Chinese cities. J. Transp. Geogr. 2020, 86, 102782. [CrossRef]

11. Xing, Y.Y.; Wang, K.; Lu, J.J. Exploring travel patterns and trip purpose of dockless bike sharing by analyzing massive bike-sharing data in Shanghai, China. J. Transp. Geogr. 2020, 87, 102787. [CrossRef]

12. Chai, Y.; Shen, J.; Zhao, Y. Activity-based approach for urban travel behavior research. Sci. Online 2015, 5, 402-409.

13. Wan, F.; Yang, G.; Li, X. A study of Hangzhou urban residents green travel choice in metro era. J. Green Sci. Technol. 2012, 8, 203-206.

14. Bai, K.; Li, C.; Zhang, C. Reference group influence and self-perceived value judgment of Xi'an urban residents' green travel behavior. Hum. Geogr. 2017, 32, 37-46.

15. Newton, P.; Meyer, D. Exploring the attitudes-action gap in household resource consumption: Does "Environmental Lifestyle" segmentation align with consumer behavior. Sustainability 2013, 5, 1211-1233. [CrossRef]

16. Ran, L.; Li, F. An analysis on characteristics and behaviors of traveling by bike-sharing. J. Transp. Inf. Saf. 2017, 35, 93-100.

17. Huang, A. Study on Structure and Dynamic Behaviors in Weighted Complex Public Transit Network Based on Passenger Flow; Beijing Jiaotong University: Beijing, China, 2014.

18. Wang, B.; Zhou, T.; Zhou, C. Statistical physics research for human behaviors, complex networks, and information mining. J. Univ. Shanghai Sci. Technol. 2012, 34, 103-117.

19. Zheng, J.; Zhang, B.; Cheng, Y. Grop choice behavior in green travel based on scale-free network. Chin. J. Manag. Sci. 2019, 27, 198-208.

20. Valkila, N.; Saari, A. Attitude behavior gap in energy issues: Case study of three different finish residential areas. Energy Sustain. Dev. 2013, 17, 24-34. [CrossRef]

21. Chardon, C.M.D.; Caruso, G. Estimating bike-share trips using station level data. Transp. Res. Part B 2015, 78, 260-279. [CrossRef]

22. Lin, J.R.; Yang, T.H. Strategic design of public bicycle sharing systems with service level constraints. Transp. Res. Part E 2011, 47, 284-294. [CrossRef]

23. Caperello, N.D.; Kurani, K.S. Households' stories of their encounters with a plugin hybrid electric vehicle. Environ. Behav. 2012, 44, 493-508. [CrossRef]

24. Faghih-Imani, A.; Eluru, N.; El-Geneidy, A.M. How land-use and urban form impact bicycle flows: Evidence from the bicycle sharing system (BIXI) in Montreal. J. Transp. Geogr. 2014, 41, 306-314. [CrossRef]

25. Saneinejad, S.; Roorda, M.J.; Kennedy, C. Modelling the impact of weather conditions on active transportation travel behaviour. Transp. Res. Part D Transp. Environ. 2012, 17, 129-137. [CrossRef]

26. Gebhart, K.; Noland, R.B. The impact of weather conditions on bikeshare trips in Washington, DC. Transportation 2014, 41, 1205-1225. [CrossRef]

27. Lee, K.H.; Ko, E.J. Relationships between neighbourhood environments and residents' bicycle mode choice: A case study of Seoul. Int. J. Urban Sci. 2014, 18, 383-395. [CrossRef]

28. González, F.; Melo-Riquelme, C.; Grange, L.D. A combined destination and route choice model for a bicycle sharing system. Transportation 2016, 43, 407-423. [CrossRef]

29. Vogel, M.; Hamon, R.; Lozenguez, G. From bicycle sharing system movements to users: A typology of Vélo'v cyclists in Lyon based on large-scale behavioural dataset. J. Transp. Geogr. 2014, 41, 280-291. [CrossRef]

30. Gao, F.; Li, S.; Wu, Z. Spatial-temporal characteristics and the influencing factors of the ride destination of bike sharing in Guangzhou city. Geogr. Res. 2019, 38, 2859-2872.

31. Wei, Z.; Mo, H.; Liu, Y. Spatial-temporal characteristics of bike-sharing: An empirical study of Tianhe District, Guangzhou. Sci. Technol. Rev. 2018, 36, 71-80.

32. The Investigation Report of Xinhua Green Travel Index; China Economic Information Service: Beijing, China, 2017. Available online: http:/ / www.xinhuanet.com//politics/2017-09/27/c_1121731198.htm (accessed on 1 August 2021).

33. Ma, J.H.; Li, J.B.; Liu, B. Solving the persistent problems of urban governance and helping to build a sophisticated Lanzhou City. Shanghai Bus. 2021, 5, 88-90.

34. Carstensen, T.A.; Olafsson, A.S.; Bech, N.M. The spatial-temporal development of Copenhagen's bicycle infrastructure 1912-2013 Geogr. Tidsskr. Dan. J. Geogr. 2015, 115, 142-156.

35. Bao, J.; Xu, C.C.; Liu, P. Exploring bike sharing travel patterns and trip purposes using smart card data and online point of interests. Netw. Spat. Econ. 2017, 17, 1231-1253. [CrossRef]

36. Mo, H.; Wei, Z.; Zhai, Q. Travel behaviors and influencing factors of bike sharing in old town: The case of Guangzhou. South Archit. 2019, 1, 7-12.

37. Zainuddin, N.B.; Min, L.H.; Teng, C.S. Sustainable transportation scheme in university: Students' intention on bike sharing system: An empirical approach. J. Glob. Bus. Soc. Entrep. 2016, 2, 144-163.

38. Kaplan, S.; Manca, F.; Nielsen, T.A.S. Intentions to use bike-sharing for holiday cycling: An application of the theory of planned behavior. Tour. Manag. 2015, 47, 34-46. [CrossRef]

39. Fishbein, M.; Ajzen, I. Belief, Attitude, Intention, and Behavior: An Introduction to Theory and Research. Contemp. Sociol. 1975. Available online: http:/ / worldcat.org/isbn/0201020890 (accessed on 1 August 2021).

40. Ajzen, I. The theory of planned behavior. Organ. Behav. Hum. Decis. Process. 1991, 50, 179-211. [CrossRef]

41. Davis, F.D. Perceived usefulness, perceived ease of use, and user acceptance of information technology. MIS Q. 1989, 13, 319-340. [CrossRef] 
42. Chen, Y.; Zha, Q.; Jing, P. Modeling and analysis of autonomous technology acceptance considering age heterogeneity. J. Jiangsu Univ. Nat. Sci. Ed. 2021, 42, 131-138.

43. Ju, P.; Zhou, J.; Chen, X.G. A study of the intent of shared use of automobiles based on TAM and TPB integration models. Mod. Manag. 2016, 36, 82-85.

44. Wang, Y.; Wang, Q. Factors affecting Beijing residents' buying behavior of new energy vehicle: An integration of technology acceptance model and theory of planned behavior. Chin. J. Manag. Sci. 2013, 21, 691-698.

45. Kraft, P.; Rise, J.; Sutton, S. Perceived difficulty in the theory of planned behavior: Perceived behavioural control or affective attitude? Br. J. Soc. Psychol. 2005, 44, 479-496. [CrossRef]

46. Zhang, W.; Li, G. Ecological compensation, psychological factors, willingness and behavior of ecological protection in the Qinba ecological function area. Resour. Sci. 2017, 39, 881-892.

47. Lao, K.F.; Wu, J. Research on influencing mechanism of consumer green consumption behavior referring to TPB. Financ. Econ. 2013, 2, 91-100.

48. Yang, H.L.; Cao, X.S.; Li, T. Analysis of willingness and influence factors of urban residents to use shared bikes: A case study of Xi'an. J. Arid. Land Resour. Environ. 2019, 33, 78-83.

49. Shao, P.; Wang, Q.; Zhao, C. Research on the factors influencing shared bicycle green use behavior and intention. J. Arid. Land Resour. Environ. 2020, 34, 64-68.

50. Chen, Y.; Wang, H. Comparison and analysis of influential on the degree of satisfaction of city bike: Based on the research involving six main districts in Beijing. Econ. Probl. 2018, 105-112.

51. Qian, J.; Wang, D.; Niu, Y. Analysis of the influencing factors of urban public bikes: A case study of Suzhou. Geogr. Res. 2014, 33, 358-371.

52. Wu, M.L. Structural Equation Modeling: Operation and Application of AMOS; Chongqing University Press: Chongqing, China, 2009.

53. Ma, J.; Yang, Y.; Yang, D. Influence of urban morphological characteristics on thermal environment. Sustain. Cities Soc. 2021, $72,103045$. 